\title{
Multiple births and maternal mental health from pregnancy to 5 years after birth: A longitudinal population-based cohort study
}

\author{
Eivind Ystrom ${ }^{1,2}$, Ted Reichborn-Kjennerud ${ }^{1,3}$, Kristian Tambs ${ }^{4}$, Per Magnus ${ }^{5,6}$, \\ Anne Mari Torgersen ${ }^{2}$ and Kristin Gustavson ${ }^{1,2}$ \\ 1) Department of Genetics, Environment and Mental Health, Division of Mental Health, Norwegian Institute of \\ Public Health (NIPH), Oslo, Norway \\ 2) Department of Psychology, Faculty of Social Sciences, University of Oslo (UiO), Oslo, Norway \\ 3) Institute of Clinical Medicine, Faculty of Medicine, UiO \\ 4) Division of Mental Health, NIPH \\ 5) Division of Epidemiology, NIPH \\ 6) Institute of Health and Society, Faculty of Medicine, UiO \\ Correspondence: Eivind Ystrom, Norwegian Institute of Public Health, P.O. box 4404 Nydalen, N-0403 Oslo, Norway \\ E-mail: eivind.ystrom@fhi.no Telephone: +47 21078334
}

\begin{abstract}
Background: There is a lack of population-based studies on multiple births and maternal mental health. Having a high-risk pregnancy by bearing two or more children is a stressful life event, and the challenges of parenting two or more children probably also lead to a high level of parental stress. There are a few results on multiple births and maternal mental health from studies on in vitro fertilization samples. The only previous cohort study on multiple birth and maternal mental health included a single measure of depressive symptoms at 9 months postpartum. We aim to estimate the relative risk for depression and anxiety after multiple birth in a population-based prospective cohort study while adjusting for factors prior and subsequent to fertilization.

Methods: We used data from 87,807 pregnancies included in the Norwegian Mother and Child Cohort study. Information on multiple birth was retrieved from the Norwegian Medical Birth Registry, and maternal mental health was assessed at $17^{\text {th }}$ and $30^{\text {th }}$ week of gestation and $0.5,1.5,3$, and 5 years postpartum. There were 1,842 plural births included in the study (i.e. 1,821 twin births and 21 higher order births). We predicted maternal mental health at each time point, subsequently adjusting for 1) factors prior to fertilization (e.g. maternal age and in vitro fertilization); 2) factors during pregnancy (e.g. hypertensive states); 3) factors at delivery (e.g. cesarean section); 4) child-related postnatal complications (e.g. intracranial hemorrhage); and 5) concurrent depression or anxiety after pregnancy.

Results: Adjusted for antecedents of plural birth, mothers expecting a plural birth had a normal risk for anxiety (RR=1.05; 95\% CI 0.92-1.20) and depression ( $R R=1.02 ; 95 \%$ CI $0.89-1.16)$ at $17^{\text {th }}$ week of gestation. However, plural birth was associated with maternal depression at $1.5,3$, and 5 years postpartum and maternal anxiety at 3 years postpartum. The trend was for the association to increase across time, and mothers of multiplets had a significant higher risk for depression at 5 years ( $R R=1.77 ; 95 \%$ CI 1.33-2.35). Fully adjusted the RR for depression was 1.51 (95\% CI 1.10-2.08). By adjusting depression for concurrent anxiety, and vice versa we found the effect of multiple pregnancy to be specific to depression and not anxiety.

Conclusions: Mothers expecting multiplets have normal mental health during pregnancy. After birth there is an increasing risk for depression up to 5 years of age. Our findings indicate that more is simply more, and mothers of multiplets have need for additional support several years postpartum.
\end{abstract}

This is an open access article distributed under the Creative Commons Attribution Licence, which permits unrestricted use, distribution, and reproduction in any medium, provided the original work is properly cited.

\section{INTRODUCTION}

There is a lack of population-based studies on multiple births and maternal mental health. Having a high-risk pregnancy by bearing two or more children is a stressful life event, and the challenges of parenting several children probably also lead to a high level of parental stress (1). Sheard et al. found that women having a multiple birth after receiving in vitro fertilization (IVF) were more likely to be depressed compared to women with single births (2). Glazebrook et al. reported mothers with multiple births after receiving IVF to have more parental stress and general mental distress 1 year postpartum compared to mothers of singletons conceived through IVF (3). Using a population-based study comprising children conceived by IVF Olivennes et al. found mothers with multiple births to have higher levels of parental stress and symptoms of depression two and five years postpartum compared to singletons conceived through IVF (4).

To the best of our knowledge there are no previous cohort studies comprising several measurements of postnatal mental health across several years. Furthermore, previous studies have to a great extent focused on depression. There are no previous longitudinal cohort studies estimating the association between multiple birth and anxiety. Estimates of mental health problems in mothers having multiple birth is of high 
importance for policy planning related to parental leave in families having multiples.

We aim to estimate the relative risk for depression and anxiety after multiple birth in a population-based prospective cohort study while adjusting for factors prior and subsequent to fertilization.

\section{METHOD}

\section{The Norwegian Mother and Child Cohort Study}

The large, ongoing Norwegian Mother and Child Cohort Study (MoBa) is conducted by the Norwegian Institute of Public Health (5,6). Between 1999 and 2008 , invitations were sent by mail to pregnant women across Norway concurrent with the routine ultrasound examination offered to all pregnant women at their local hospital around week 17 of pregnancy. The study includes 114,500 children, 95,200 mothers and 75,200 fathers enrolled during the recruitment period. The participation rate was $40.6 \%$. Informed consents and approvals by the Regional Committee for Medical Research Ethics and Norwegian Data Inspectorate were obtained. Self-report questionnaires were sent to the mothers and fathers at 17 weeks of gestation, and to mothers at 22 and 30 weeks of gestation and at intervals after birth when children were 6 months, 1.5, 3, and 5 years old. Response rates for mothers who had consented to join the study were $91 \%$ to $95 \%$ during pregnancy and $84.8 \%, 72.4 \%, 58.5 \%$, and $53.4 \%$ in the waves after birth. Pregnancy and birth records from the Medical Birth Registry of Norway (MBRN) were linked to the MoBa database (7). The current study is based on version 7 of the data files, released for research in 2012. There were 90,759 births where the children were live born and data on one or more of the outcome variables were valid. Among these, 3,669 $(4.0 \%)$ had missing data on one of the predictors. These cases were not included in further analyses. In total there were $85,248(97.9 \%)$ single births, 1,821 $(2,1 \%)$ twin births, and $21(0.024 \%)$ higher order births included in the analyses.

\section{Measures}

Information on plural birth, administrative health region in Norway, maternal age, paternal age, primiparity, in vitro fertilization (IVF), BMI at gestation, vaginal bleeding during pregnancy, hypertensive condition during pregnancy, induction of labor, cesarean section, episiotomy, extraction by forceps or vacuum, transfer to neonatal ward, birth weight, preterm birth, birth length, head circumference, apgar score, respiratory distress syndrome, continuous positive airway pressure (CPAP) treatment, respiratory treatment, intracranial hemorrhage, systemic antibiotic treatment, icterus treatment, and birth defects was retrieved from the MBRN. Marital status was retrieved from the questionnaire at $17^{\text {th }}$ week of gestation. We assessed maternal symptoms of anxiety and depression using a short version of the Hopkins Symptom Checklist
(SCL-8) (8). The SCL-8 is an 8-item self-report instrument designed to assess psychological distress, in particular anxiety and depression. The response categories range from one to four (not bothered to very much bothered). The four-item anxiety and depression measures correlate 0.90 and 0.92 , respectively, with the full-scale measures included in the SCL-25, and have alpha reliabilities of 0.78 and 0.83 , respectively (8). We computed the average score across the four items for anxiety and depression, respectively, and defined cases to be above cut off for anxiety or depression with a score greater than 1.75 .

\section{Statistics}

We estimated the association between multiple birth and the outcomes while adjusting for covariates by generalized estimating equations in SPSS version 20.0. Covariates were accumulatively added to the model. First, we estimated crude associations. Next, factors prior to fertilization (i.e. putative antecedents of multiple birth) were added to the model. In the following steps we adjusted for factors subsequent to fertilization (i.e. putative consequences of multiple birth). Hence, these factors could also be putative mediators. Although this implies overadjustment, we wanted to investigate to what extent the effect of multiple birth on anxiety and depression represented factors during pregnancy, factors at delivery, or child-related postnatal factors. Last, we adjusted for concurrent anxiety or depression after pregnancy to investigate to what extent the effect of plural birth is specific to either form of mental health problem.

\section{RESULTS}

The final sample consisted of 85,248 (97.9\%) single births, $1,821(2,1 \%)$ twin births, and $21(0.024 \%)$ higher order births. The prevalence of depression and anxiety is presented in Table 1 . At $30^{\text {th }}$ week of gestation $9.3 \%$ of the women were depressed according to the cut-off. Thereafter the prevalence increased to $12.5 \%$ at 3 years postpartum, and the prevalence decreases to $8.5 \%$ at 5 years postpartum. The prevalence of anxiety is $6.0 \%$ at $30^{\text {th }}$ week of gestation and was thereafter more stable. The prevalence of anxiety dropped to $3.7 \%$ at 5 years postpartum.

Table 1. Prevalence of depression and anxiety and number of cases with valid follow-up data among a total of 94499 pregnancies.

\begin{tabular}{lrc}
\hline & \multicolumn{1}{c}{ Depression } & Anxiety \\
\hline Week 30 of gestation & $9.3 \%(\mathrm{n}=90213)$ & $6.0 \%(\mathrm{n}=90191)$ \\
0.5 years postpartum & $9.5 \%(\mathrm{n}=84689)$ & $4.8 \%(\mathrm{n}=84702)$ \\
1.5 years postpartum & $12.1 \%(\mathrm{n}=71813)$ & $5.1 \%(\mathrm{n}=71827)$ \\
3 years postpartum* & $12.5 \%(\mathrm{n}=54622)$ & $5.8 \%(\mathrm{n}=54633)$ \\
5 years postpartum* & $8.5 \%(\mathrm{n}=19189)$ & $3.7 \%(\mathrm{n}=19188)$ \\
\hline
\end{tabular}

*Data collection not completed. 
A description of the mothers with single or multiple pregnancies is presented in Table 2 . The mothers with a multiple pregnancy differed from the mothers with single pregnancies with regard to a range of factors prior to fertilization: geography, maternal age, paternal age, marital status, parity, and IVF; and with regard to factors subsequent to fertilization: BMI at gestation, bleeding during pregnancy, hypertensive condition during pregnancy, induction of labor, cesarean section, episiotomy, transfer to neonatal ward, birth weight, preterm birth, infant length, head circumference, 5minute Apgar score, respiratory distress syndrome, CPAP- treatment, respiratory treatment, intracranial hemorrhage, systemic antibiotic treatment, icterus treatment, and birth defects.

The relative risk for anxiety and depression after multiple birth is presented in Table 3. Overall, women expecting a multiple birth had the same risk for anxiety and depression during pregnancy as women expecting a single birth. After adjusting for factors prior to fertilization women with multiple birth were more likely to suffer from anxiety at 3 years postpartum $(\mathrm{RR}=1.36 ; 95 \% \mathrm{CI} 1.07-1.73)$ and more likely to suffer from depression at 1.5 years $(\mathrm{RR}=1.24 ; 95 \% \mathrm{CI}$ $1.07-1.43), 3$ years $(\mathrm{RR}=1.20 ; 95 \% \mathrm{CI} 1.02-1.42)$, and 5 years $(\mathrm{RR}=1.77 ; 95 \%$ CI 1.33-2.35) postpartum.

Factors during pregnancy did not account for the risk for anxiety and depression during the first postpartum years, but factors at delivery and child-related postnatal complications did account for some of the risk for anxiety and depression after multiple birth. However, after sequentially adjusting for all factors prior and post fertilization mothers having given a multiple birth still had an increased risk for depression at 5 years $(\mathrm{RR}=1.45 ; 95 \%$ CI $1.06-1.97)$.

As a last step we adjusted for concurrent depression or anxiety. After this adjustment multiple birth was associated with depression at 0.5 years $(\mathrm{RR}=1.18$; 95\% CI 1.01-1.39), 1.5y ( $\mathrm{RR}=1.22$; 95\% CI 1.05 $1.42)$, and 5 years $(\mathrm{RR}=1.51 ; 95 \% \mathrm{CI} 1.10-2.08)$ postpartum. However, after adjusting for concurrent depression multiple birth was not associated with anxiety at $1.5,3$, and 5 years, respectively, but was negatively associated with anxiety at 0.5 years $(R R=$ 0.69 ; $95 \%$ CI 0.55-0.87) postpartum.

\section{Discussion}

In the current study we aimed to estimate the relative risk for depression and anxiety after multiple birth in a population-based prospective cohort study while adjusting for factors prior and subsequent to fertilization. We found that after accounting for putative antecedents of multiple birth, multiple birth was associated with depression the first 5 years postpartum, and that the effect increased with time. Multiple birth did not show a comparable association with anxiety, but multiple birth was associated with anxiety at 3 years postpartum. When we explored factors subsequent to fertilization that could mediate the observed association, we found that factors during pregnancy was of no importance to the observed association with postpartum mental health, but that factors at delivery and childrelated postnatal complications could account for some of the effect. When we in a last step explored to what extent the effect of multiple birth on postpartum anxiety and depression was specific to either anxiety and depression, we found the effect to be highly specific to depression. In fact, multiple birth was negatively associated with risk specific to anxiety and not shared with depression at 0.5 years postpartum.

It appears that mothers of multiples start out with equal mental health as mothers of singletons, that their mental health deteriorates with time, and that the poorer mental health cannot fully be explained by medical factors during pregnancy, at delivery or childrelated postnatal complications. It appears that the detrimental effect is specific to depression. Such a pattern conforms with the wear and tear of taking care of more than one toddler at a time (1), and is in line with previous research on women undergoing IVF treatment (2-4). The reduction of effect of multiple birth on anxiety and depression after adjusting for factors at delivery and child-related postnatal complications shows that some of the difficulties from having multiplets can be attributed to the general difficulties of having children subjected to complicated births or with extreme immaturity, intracranial hemorrhage, or serious birth defects.

After adjusting for concurrent anxiety post partum, we found that the effect of multiple birth was specific to depression. Maternal depression may affect child development. Children of depressed mothers are at risk for delayed cognitive and language development (9, $10)$, mental health problems (11-13), suboptimal diet (14-16), and a number of different social, emotional, and behavioral problems $(9,11,17,18)$. Population screeners for depression measure feelings of everything being an effort. Although mothers in Norway enjoy a 49 week maternity leave with $80 \%$ pay, mothers of twins only receive 7 additional weeks. One might therefore argue that the total child rearing effort per week of leave given is higher for mothers of multiplets than for mothers of singletons. This also conforms with the findings that risk for depression after multiple birth reach significance after 18 months; at a time where payed leave is over and most Norwegian mothers are back at work. One might hence suspect that the effect would be larger at an earlier time after birth in societies with shorter maternity leave.

There are limitations to the current study. One, the participation rate to the study was only $40.6 \%$. Nilsen et al. found that the moderate participation rate of the MoBa study had an impact on prevalence estimates, but not on association estimates (19). We may therefore suspect the prevalence estimates of anxiety and depression to be biased, but the association estimates to be more robust. Two, one could expect the partici- 
Table 2. Characteristics of mothers with single and multiple pregnancies.

\begin{tabular}{|c|c|c|c|}
\hline & $\begin{array}{c}\text { Single pregnancy } \\
\mathrm{n}=85,248\end{array}$ & $\begin{array}{l}\text { Multiple pregnancy } \\
n=1,842\end{array}$ & $\begin{array}{l}\text { Risk } \\
\text { ratio }\end{array}$ \\
\hline \multicolumn{4}{|l|}{ Factors prior to fertilization } \\
\hline \multicolumn{4}{|l|}{ Administrative health region in Norway } \\
\hline South / East & $52.4 \%$ & $49.7 \%$ & 0.95 \\
\hline West & $26.5 \%$ & $30.4 \%$ & 1.15 \\
\hline Middle & $15.1 \%$ & $14.4 \%$ & 0.95 \\
\hline North & $5.9 \%$ & $5.4 \%$ & 0.92 \\
\hline Unknown & $0.2 \%$ & $0.0 \%$ & - \\
\hline \multicolumn{4}{|l|}{ Maternal age } \\
\hline$\leq 24 \mathrm{y}$ & $12.4 \%$ & $6.2 \%$ & 0.50 \\
\hline $25-29 y$ & $34.0 \%$ & $27.1 \%$ & 0.80 \\
\hline $30-34 y$ & $36.9 \%$ & $45.3 \%$ & 1.23 \\
\hline $35-39 y$ & $14.7 \%$ & $19.5 \%$ & 1.33 \\
\hline$\geq 40 \mathrm{y}$ & $2.1 \%$ & $2.0 \%$ & 0.95 \\
\hline \multicolumn{4}{|l|}{ Paternal age } \\
\hline$\leq 24 \mathrm{y}$ & $5.5 \%$ & $2.9 \%$ & 0.53 \\
\hline $25-29 y$ & $24.0 \%$ & $17.4 \%$ & 0.73 \\
\hline 30-34y & $37.7 \%$ & $39.8 \%$ & 1.06 \\
\hline $35-39 y$ & $22.4 \%$ & $28.6 \%$ & 1.28 \\
\hline$\geq 40 \mathrm{y}$ & $9.9 \%$ & $10.9 \%$ & 1.10 \\
\hline Unknown paternal age & $0.5 \%$ & $0.4 \%$ & 0.80 \\
\hline Marital status (single) & $4.6 \%$ & $3.1 \%$ & 0.67 \\
\hline Primipara & $52.7 \%$ & $48.7 \%$ & 0.92 \\
\hline In vitro fertilization & $2.2 \%$ & $24.4 \%$ & 11.09 \\
\hline \multicolumn{4}{|l|}{ Factors subsequent to fertilization } \\
\hline \multicolumn{4}{|l|}{ Under- and overweight at gestation } \\
\hline Underweight at gestation (BMI 18.5-25) & $3.1 \%$ & $2.3 \%$ & 0.74 \\
\hline Overweight at gestation (BMI 25-30) & $20.6 \%$ & $21.3 \%$ & 1.03 \\
\hline Obesity at gestation $(\mathrm{BMI}>30)$ & $9.1 \%$ & $11.3 \%$ & 1.24 \\
\hline Unknown BMI at gestation & $4.1 \%$ & $2.5 \%$ & 0.61 \\
\hline Vaginal bleeding during pregnancy & $5.0 \%$ & $6.9 \%$ & 1.38 \\
\hline Hypertensive condition during pregnancy & $6.1 \%$ & $13.9 \%$ & 2.28 \\
\hline Induction of labor & $13.3 \%$ & $29.3 \%$ & 2.20 \\
\hline Cesarean section & $14.4 \%$ & $42.1 \%$ & 2.92 \\
\hline Episiotomy & $19.1 \%$ & $16.4 \%$ & 0.86 \\
\hline Extraction by forceps or vacuum & $10.5 \%$ & $9.2 \%$ & 0.88 \\
\hline \multicolumn{4}{|l|}{ Transfer to neonatal ward } \\
\hline Yes & $7.9 \%$ & $37.7 \%$ & 4.77 \\
\hline Unknown & $5.9 \%$ & $5.1 \%$ & 0.86 \\
\hline \multicolumn{4}{|l|}{ Birth weight } \\
\hline Other low birth weight (1000-2499g) & $2.9 \%$ & $39.1 \%$ & 13.48 \\
\hline Extremely low birth weight $(<1000 \mathrm{~g})$ & $0.4 \%$ & $3.0 \%$ & 7.50 \\
\hline Unknown birth weight & $0.2 \%$ & $0.2 \%$ & 1.00 \\
\hline \multicolumn{4}{|l|}{ Preterm birth } \\
\hline Other preterm infant (28-36wk) & $4.9 \%$ & $46.7 \%$ & 9.53 \\
\hline Extreme immaturity $(<28 w k)$ & $0.6 \%$ & $3.2 \%$ & 5.33 \\
\hline Unknown age of gestation & $0.4 \%$ & $0.8 \%$ & 2.00 \\
\hline \multicolumn{4}{|l|}{ Infant length } \\
\hline Length $<10$ th percentile & $9.2 \%$ & $56.0 \%$ & 6.09 \\
\hline Unknown length & $2.1 \%$ & $6.1 \%$ & 2.90 \\
\hline \multicolumn{4}{|l|}{ Head circumference } \\
\hline Head circumference $<10$ th percentile & $11.0 \%$ & $44.5 \%$ & 4.05 \\
\hline Unknown head circumference & $2.2 \%$ & $8.0 \%$ & 3.64 \\
\hline \multicolumn{4}{|l|}{ Apgar score (5-minute) } \\
\hline $0-3$ & $0.6 \%$ & $1.4 \%$ & 2.33 \\
\hline $4-6$ & $1.0 \%$ & $2.0 \%$ & 2.00 \\
\hline $7-10$ & $98.1 \%$ & $96.1 \%$ & 0.98 \\
\hline Unknown apgar score & $0.4 \%$ & $0.5 \%$ & 1.25 \\
\hline Respiratory distress syndrome & $0.9 \%$ & $8.1 \%$ & 9.00 \\
\hline CPAP-treatment & $0.8 \%$ & $6.3 \%$ & 7.88 \\
\hline Respiratory treatment & $0.3 \%$ & $2.4 \%$ & 8.00 \\
\hline Intracranial hemorrhage & $0.2 \%$ & $1.4 \%$ & 7.00 \\
\hline Treated with systemic antibiotics & $2.4 \%$ & $8.0 \%$ & 3.33 \\
\hline Icterus treatment & $7.7 \%$ & $23.6 \%$ & 3.06 \\
\hline \multicolumn{4}{|l|}{ Birth defects } \\
\hline Serious birth defects & $2.9 \%$ & $6.3 \%$ & 2.17 \\
\hline Other birth defects & $2.2 \%$ & $1.7 \%$ & 0.77 \\
\hline
\end{tabular}

$* \mathrm{p}<.05$ 
Table 3. Relative risk for pre and postpartum anxiety and depression in women with multiple pregnancies.

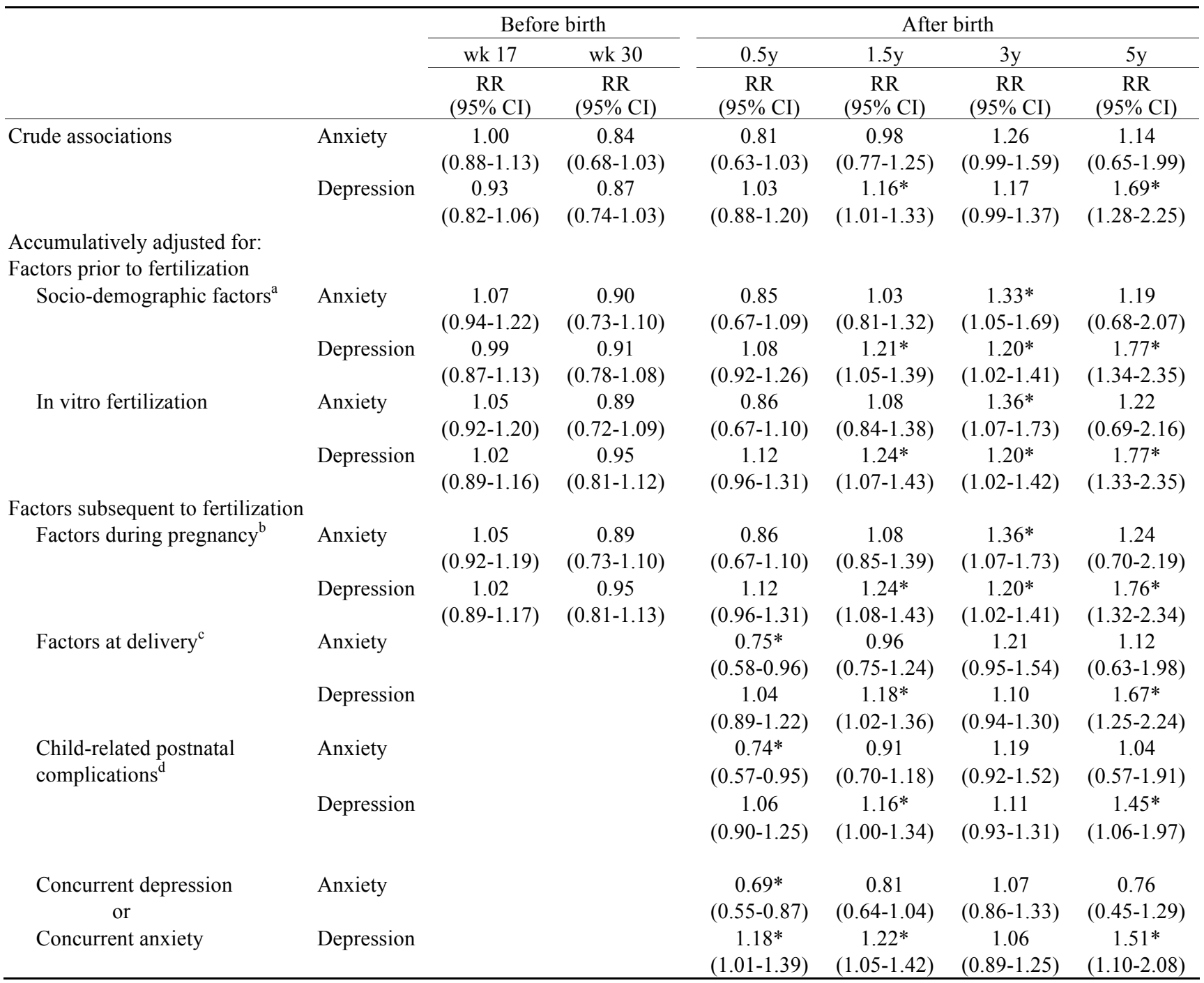

${ }^{*} \mathrm{p}<.05$

${ }^{a}$ Administrative health region, maternal age, paternal age, marital status, and parity.

${ }^{\mathrm{b}}$ Underweight, overweight or obesity at gestation; vaginal bleeding; and hypertensive condition.

${ }^{\mathrm{c}}$ Induction of labor, cesarean section, episiotomy, extraction by forceps or vacuum extractor, and transfer to neonatal ward.

${ }^{\mathrm{d}}$ Extremely low birth weight (ICD P07.0), other low birth weight (ICD P07.1), extreme immaturity (ICD P07.2), other preterm infant (ICD P07.3), length $<10$ th percentile, head circumference $<10$ th percentile, five-minute apgar score, respiratory distress syndrome, intracranial hemorrhage, treated with systemic antibiotics, respiratory treatment, continuous positive airway pressure (CPAP)-treatment, icterus treatment, serious birth defects, and other birth defects.

pation rate among mothers with plural birth to be lower. However, the rate of twin and higher order births in 2005 was $1.83 \%$ and $0.04 \%$ in Norway. This is close to the rate among the MoBa participants. Three, we only used short-form screeners to measure anxiety and depression. Future studies should investigate the association between multiple birth and parental mental health using a linkage between the MBRN and the Norwegian Patient Registry (20). Four, since the $\mathrm{MoBa}$ only contains follow-up data on the mothers we were not able to study the impact on the mental health of the fathers. It would be interesting to see in future studies to what extent the effect of multiple births on mental health is comparable in mothers and fathers.
The clinical implication of the current study is that since mothers with multiple births appears to be more often stressed by their maternal obligations, relevant authorities, such as the Ministry of Health and Care Services, should consider an extension of the parental leave after multiple birth.

\section{ACKNOWLEDGEMENTS}

We would like to thank the participants of the Norwegian Mother and Child Cohort. The Norwegian Mother and Child Cohort Study is supported by the Norwegian Ministry of Health and the Ministry of Education and Research, NIH/NIEHS (contract no NO-ES-75558), NIH/NINDS (grant no.1 UO1 NS 047537-01), and the Norwegian Research Council/FUGE (grant no. 151918/S10). 


\section{REFERENCES}

1. Robin M, Corroyer D, Casati I. Childcare patterns of mothers of twins during the first year. J Child Psychol Psychiatry 1996; 37 (4): 453-460.

2. Sheard C, Cox S, Oates M, Ndukwe G, Glazebrook C. Impact of a multiple, IVF birth on post-partum mental health: a composite analysis. Hum Reprod 2007; 22 (7): 2058-2065.

3. Glazebrook C, Sheard C, Cox S, Oates M, Ndukwe G. Parenting stress in first-time mothers of twins and triplets conceived after in vitro fertilization. Fertil Steril 2004; 81 (3): 505-511.

4. Olivennes F, Golombok S, Ramogida C, Rust J. Behavioral and cognitive development as well as family functioning of twins conceived by assisted reproduction: findings from a large population study. Fertil Steril 2005; 84 (3): 725-733.

5. Magnus P, Irgens LM, Haug K, Nystad W, Stoltenberg C, The MoBa Study Group. The Norwegian Mother and Child Cohort Study. Int J Epidemiol 2006; 35 1146-1150.

6. Magnus P. The Norwegian Mother and Child Cohort Study (MoBa) - new research possibilities. Norsk Epidemiologi 2007; 17 (2): 107-110.

7. Irgens LM. The Medical Birth Registry of Norway. Epidemiological research and surveillance throughout 30 years. Acta Obstet Gynecol Scand 2000; 79 (6): 435-439.

8. Tambs K. Valg av spørsmål til kortversjoner av etablerte psykometriske instrumenter. Forslag til framgangsmåte og noen eksempler [Norwegian]. I: Sandanger I, Sørensen T, red. Ubevisst sjeleliv og bevisst samfunnsliv: psykisk helse $i$ en sammenheng: festskrift til Tom Sørensen på hans 60-årsdag, Nittedal: Nordkyst psykiatri, 2004.

9. Grace SL, Evindar A, Stewart DE. The effect of postpartum depression on child cognitive development and behavior: a review and critical analysis of the literature. Arch Womens Mental Health 2003; 6 (4): 263-274.

10. Sohr-Preston SL, Scaramella LV. Implications of timing of maternal depressive symptoms for early cognitive and language development. Clin Child Fam Psychol Rev 2006; 9 (1): 65-83.

11.Goodman SH, Rouse MH, Connell AM, Broth MR, Hall CM, Heyward D. Maternal depression and child psychopathology: a meta-analytic review. Clin Child Fam Psychol Rev 2011; 14 (1): 1-27.

12. Lieb R, Isensee B, Höfler M, Pfister H, Wittchen HU. Parental major depression and the risk of depression and other mental disorders in offspring: a prospective-longitudinal community study. Arch Gen Psychiatry 2002; 59 (4): $365-374$.

13. McAdams TA, Neiderhiser JM, Rijsdijk FV, Narusyte J, Lichtenstein P, Eley TC. Accounting for genetic and environmental confounds in associations between parent and child characteristics: A systematic review of children-of-twins studies. Psychol Bull 2014; 140 (4): 1138-1173.

14. Ystrom E, Niegel S, Vollrath ME. The impact of maternal negative affectivity on dietary patterns of 18-monthold children in the Norwegian Mother and Child Cohort Study. Matern Child Nutr 2009; 5 (3): 234-242.

15. Ystrom E, Barker M, Vollrath ME. Impact of mothers' negative affectivity, parental locus of control, and child-feeding practices on dietary patterns of three-year-old children. The MoBa Cohort Study. Matern Child Nutr 2012; 8 (1): 103-114.

16. Ystrom E. Breastfeeding cessation and symptoms of anxiety and depression: a longitudinal cohort study. BMC Pregnancy Childbirth 2012; 12: 36.

17. Cox AD, Puckering C, Pound A, Mills M. The impact of maternal depression in young children. $J$ Child Psychol Psychiatry 1987; 28 (6): 917-928.

18. Downey G, Coyne JC. Children of depressed parents: an integrative review. Psychol Bull 1990; 108 (1): 50-76.

19. Nilsen RM, Vollset SE, Gjessing HK et al. Self-selection and bias in a large prospective pregnancy cohort in Norway. Paediatr Perinat Epidemiol 2009; 23 (6): 597-608.

20. Bakken IJ, Nyland K, Halsteinli V, Kvam U, Skjeldestad F. Norsk pasientregister: Administrativ database med mange forskningsmuligheter. Norsk Epidemiologi 2004; 14 (1): 65-69. 